\title{
Artigos
}

\section{O Serviço Sanitário do Estado de São Paulo e a gripe espanhola em 1918}

\author{
The São Paulo State \\ Sanitary Service and the \\ Spanish flu in 1918
}

\author{
Rodrigo Antonio Ramos Galvão'
}

1.

Historiador formado pela

Faculdade de Filosofia, Letras e

Ciências Humanas da Universidade de São Paulo (FFLCH-USP) rodrigo. galvao@usp.br

\begin{abstract}
Resumo
Este artigo tem como objetivo analisar a atuação do Serviço Sanitário do Estado de São Paulo durante a epidemia de gripe espanhola em 1918. A principal fonte de análise foi o relatório A Grippe Epidemica no Brazil e especialmente em São Paulo, considerando as legislações e registros da imprensa na época e a bibliografia sobre o tema. Busca-se avaliar o impacto da epidemia no Estado pelas narrativas acerca do desempenho do Serviço Sanitário e o que o surto de 1918 representou na trajetória dessa instituição.
\end{abstract}

\section{Palavras-chave}

Serviço Sanitário. Estado de São Paulo. Gripe espanhola. Epidemia. História da Saúde Pública.

\section{Abstract \\ The paper analyzes the performance of the São Paulo State Sanitary Service during the Spanish flu epidemic in 1918. The main source of analysis was the report $A$ Grippe Epidemica no Brazil e especialmente em São Paulo, considering the legislation and press records at the time and the bibliography on the subject. It evaluates the impact of the epidemic in the State of São Paulo by the narratives about the performance of the Sanitary Service and what the 1918 epidemic represented in the trajectory of this institution.}




\section{Keywords}

Sanitary Service. São Paulo State. Spanish flu. Epidemic. History of Public Health.

\section{Introdução}

0 Após a pandemia de 1918, três livros foram publicados sobre a gripe espanhola no Brasil. 0 primeiro, no Rio de Janeiro, A propósito da pandemia de grippe de 1918 (1919) de Carlos Seidl, Diretor Geral de Saúde Pública (19121918), expõe opiniões, debates, discussões acadêmicas e embates com a imprensa durante a epidemia na capital da República. 0 segundo, em São Paulo, A Grippe Epidemica no Brazil e especialmente em São Paulo (1920) de Carlos Luiz Meyer e Joaquim Rabello Teixeira, médicos do Serviço Sanitário, apresenta dados, informações, relações de serviços prestados, boletins oficiais e relatos das cidades do interior e dos Estados brasileiros. E o terceiro, também no Rio de Janeiro, O pandemônio de 1918 (1924) do médico Moncorvo Filho, descreve a mobilização da instituição que dirigia, o Departamento da Criança do Brasil, durante a pandemia (BERTUCCI-MARTINS, 2002, p. 2-3).

Os dois livros de Seidl e Moncorvo Filho, publicados na então capital, relatam a epidemia gripal através de experiências muito pessoais (Idem, 2002). Já o de Carlos Luiz Meyer, ex-diretor do Laboratório de Bacteriologia do Estado e diretor da Demografia Sanitária, e Joaquim Rabello Teixeira, Diretor da Secretaria do Serviço Sanitário, a relatam impessoalmente como documento oficial, mas enaltecendo a atuação do Serviço Sanitário. No prefácio do documento, Arthur Neiva, Diretor do Serviço Sanitário durante a pandemia (19171919), escreve:

Quem assistiu aos horrores ocorridos no Rio de Janeiro, onde a entrosagem social se desorganizou totalmente, e presenciou os sucessos de S. Paulo, onde a cooperação da população, da imprensa, das associações de toda a casta, de mãos dadas com os poderes públicos, permitiram enfrentar a situação com orgulhoso confronto com as sociedades mais cultas do mundo, terá de reconhecer os ingentes 
Destacam-se outros trabalhos desta autora como "Conselhos ao povo": educação contra a influenza de 1918 (2003); Aprendendo com o passado: Campinas e a gripe de 1918 (2005); Entre doutores e para os leigos: fragmentos do discurso médico na influenza de 1918 (2005); Gripe A, uma nova" espanhola"? (2009); Memória que educa. Epidemias do final do século XIX e início do XX (2005) e A onipresença do medo na influenza de 1918 (2009). esforços de Ss. Excas. os srs. Dr.s Presidente do Estado e Secretário do Interior. (MEYER; TEIXEIRA, 1920, p. III-IV).

Com 654 páginas, o relatório de Meyer e Teixeira se inicia com um breve resumo da epidemia em São Paulo. Pondera-se que o Serviço Sanitário do Estado, a par do que acontecia no Rio de Janeiro, já se preparava para enfrentar a moléstia e apresenta considerações sobre seu impacto na capital paulista. Depois, narram-se os primeiros casos de gripe em São Paulo, assim como as medidas tomadas pelo Serviço Sanitário, a atuação das Delegacias de Saúde, a organização da iniciativa privada e a estatística geral com os casos de gripe e mortalidade na cidade de São Paulo.

0 relatório apresenta, em seguida, as comunicações gerais à imprensa pela Diretoria do Serviço Sanitário de 16 de outubro a 19 de dezembro de 1918, o que inclui a atuação das instituições públicas no combate à gripe, a questão epidemia no Interior do Estado com as localidades socorridas, dados e informações das Delegacias de Saúde dos municípios e taxas de mortalidade da gripe no interior. Ao fim, o documento aborda a gripe na capital, Rio de Janeiro, e nos Estados do Brasil, alguns com dados mais completos sobre o número de casos e mortalidade geral, seguidos pelo anexo da relação de localidades no interior de São Paulo que mantiveram médicos e hospitais municipais durante a epidemia de gripe.

Trabalhos recentes sobre a gripe espanhola - $A$ Gripe Espanhola em São Paulo, 1918: Epidemia e Sociedade (1986), de Claudio Bertolli Filho, que se debruça sobre o impacto e o panorama da epidemia na capital paulista; Influenza, a medicina enferma: Ciência e práticas de cura na época da gripe espanhola em São Paulo (2002), de Liane Maria Bertucci-Martins², que aborda, sobretudo, a terapêutica no periodo; e Um cenário Mefistofélico: a gripe espanhola no Rio de Janeiro (2003), de Adriana da Costa Goulart, que analisa a epidemia na então capital - encontraram no relatório paulista uma fonte de extrema relevância, imprescindivel para o estudo do tema. Já na época em que foi publicado, o documento era apontado por Arthur Neiva em seu prefácio como "a única publicação que se ocupa de tão importante matéria, de maneira a dar uma impressão aproximada do que foi a epidemia gripal em todos os Estados brasileiros, com 
Referimo-nos à legislação estadual pertinente à organização do Serviço Sanitário, Códigos Sanitários e a legislação criada durante a epidemia de 1918. especialidade no de S. Paulo" (In: MEYER; TEIXEIRA, 1920, p. III).

As outras fontes do período, como artigos de jornais, se contrapõem à narrativa do relatório e se fazem igualmente relevantes para a pesquisa. Pelo uso do relatório como fonte principal, em contraste com os registros da imprensa, e a legislação pertinente ${ }^{3}$, esta análise se volta para a atuação do Serviço Sanitário, considerando sua consolidação até 1918, a reação à epidemia e as ações tomadas, assim como suas insuficiências e repercussão na imprensa. Uma contribuição ao tema cujo prefácio de Neiva alerta: "O historiador que, no futuro, procurar descrever as principais epidemias que assolaram o Brasil, com muita dificuldade poderá fazer ideia da formidável calamidade que foi a gripe epidêmica" (Idem, 1920).

\section{A organização do Serviço Sanitário do Estado de São Paulo até 1918}

Criado em 1891 subordinado à Secretaria de Negócios do Interior, o Serviço Sanitário do Estado foi organizado em 1892, inicialmente, com quatro laboratórios: o Laboratório de Análises Químicas e Bromatológicas, o Laboratório Bacteriológico, o Instituto Vacinogênico e o Laboratório Farmacêutico (SÃO PAULO (Estado), 1892). Já em 1917, em sua quarta reorganização, somavam-se a esses laboratórios o Desinfectório Central; a Estatística Demografosanitária; os Hospitais de isolamento, Lazaretos, Postos Quarentenários e de Observação; o Instituto Soroterápico de Butantan; o Instituto de Proteção à Primeira infância e Inspeção das Amas de Leite; o Instituto Pasteur; a Inspetoria dos Serviços de Profilaxia Geral e o Almoxarifado do Serviço Sanitário; além da divisão do Estado em sete Delegacias de Saúde: São Paulo, Santos, Campinas, Ribeirão Preto, São Carlos, Guaratinguetá e Botucatu (SÃO PAULO, (Estado), 1917).

0 aumento da envergadura do Serviço Sanitário correspondia à crescente necessidade de sanear os portos, as cidades e o campo devido à expansão cafeeira, à imigração, ao crescimento da indústria e à urbanização. A ascensão da bacteriologia no período, que postulava a igualdade de todos ante a ameaça da doença (HOCHMANN, 2006, p. 50), e mesmo a análise da medicina social acerca da 
socialização do corpo enquanto força de trabalho, manutenção e conservação desta (FOUCAULT, 1984, p. 79-80), demandavam ações sanitárias, sobretudo na regulação da vida social e urbana, e principalmente na capital paulista, onde se concentrava a maior parte das instituições subordinadas ao Serviço Sanitário e cuja população aumentara de 64.934 habitantes em 1890 (BRASIL, 1890) para 528.295 habitantes em 1918 (MEYER; TEIXEIRA, 1920, p. 4).

Após a reorganização do Serviço Sanitário em 1893 e o estabelecimento do Código Sanitário em 1894, a legislação passou a cobrir todas as áreas de saneamento urbano e higiene pessoal, além de a fornecer regras a serem seguidas pelas municipalidades do Estado; enquanto isso, o Serviço Sanitário se encarregava da luta contra as doenças epidêmicas (BLOUNT, 1972). A relutância das câmaras municipais, que esperavam que o Serviço Sanitário iniciasse todas as obras de higiene e saneamento, levou à reorganização do Serviço e suas atividades com a nova legislação de 1896. 0 Estado passou reforçar sua presença nos assuntos de higiene local, a se responsabilizar pela execução de medidas ofensivas e defensivas quanto à vigilância sanitária e até a assumir o poder completo dos serviços locais de saúde pública nos municipios (Idem, 1972).

Durante a gestão de Emílio Ribas (1898-1917), a organização do Serviço Sanitário praticamente extinguiu os serviços municipais de saúde (MASCARENHAS, 2006). Grandes medidas sanitárias foram aplicadas, caracterizadas pela luta contínua contra as doenças endêmicas e epidêmicas com a expansão das atividades e da autoridade estadual para incluir áreas da saúde pública não previstas na legislação anterior a 1896. 0 resultado foi a diminuição da mortalidade no Estado e na capital e o controle eficaz das doenças epidêmicas mais temidas (BLOUNT, 1972). $\mathrm{Na}$ cidade de São Paulo, o coeficiente de mortalidade (número de óbitos por mil habitantes), que em 1894 apresentava uma taxa de 10,6, diminuiu para 4,2 em 1899, mantendo-se sem grandes alterações até a epidemia de 1918. Já as doenças infectocontagiosas reduziram, no obituário geral, de 26,5\% em 1894 para 14,9\% em 1917. As principais delas eram tuberculose (responsável por 39,9\% das mortes), febre tifóide (responsável por 9,4\% das mortes), malária (responsável por 7,9\% das 
4.

Correio Paulistano 27/04/1918.

p. 1 mortes), sarampo (responsável por 6,1\% das mortes) e influenza (responsável por 4,1\% das mortes) (RAMOS apud BERTOLLI, 2003, p. 54).

As reformas de 1911 e 1917 prosseguiram com a bem-sucedida expansão do Serviço Sanitário, aumentando seus trabalhos na capital paulista com a criação de novos equipamentos públicos de saúde e ampliando o controle estadual nas regiões do interior, com destaque para 0 policiamento sanitário nas fazendas e em outros estabelecimentos da zona rural a partir da reforma de 1917 (BLOUNT, 1972). Uma investidura que desde sua criação resultaria no mais completo Serviço Sanitário do Brasil

Em 1917, o médico Arthur Neiva substitui Emílio Ribas na direção do Serviço Sanitário, permanecendo no cargo até 1919. Antes de assumir, já se esperava por um novo Código Sanitário no Estado, que se estabeleceu em abril de 1918. Este, mais robusto que o anterior, ditava novas diretrizes e atualizações, sedimentando a estrutura administrativa da legislação de 1917, fomentando o saneamento rural e estabelecendo novas regulamentações para construções, funcionamento de estabelecimentos, exercício de profissões da área da saúde e fiscalização sanitária (SÃO PAULO (Estado), 1918).

0 Código representava a maior iniciativa do Estado de São Paulo na regulação sanitária e foi bem recebido pela Academia Nacional de Medicina que, por meio de um ofício de seu secretário geral Olympio da Fonseca publicado no Correio Paulistano em 27 de abril de 1918, comunicava ao Secretário do Interior do Estado, Oscar Rodrigues Alves, um voto de aplauso aos "promotores da inestimável obra que é o Código Sanitário de S. Paulo, cuja utilidade não se limita ao glorioso Estado, mas a todo Brasil."4

No mês seguinte, em 17 de maio de 1918, uma circular publicada no Correio Paulistano por Rodrigues Alves comunicava aos prefeitos do Estado o envio de um exemplar do Código Sanitário, abordando os artigos 5 a 9, que tratavam do serviço sanitário dos municípios e sua relação com o Serviço Geral. Nela, o Secretário realçava que "na organização da higiene dos municípios deverão as Câmaras tomar como modelo o serviço sanitário geral" e que "o governo tomará na maior consideração as 
5.

Correio Paulistano 17/03/1918.

p. 2

6.

Correio Paulistano 23/09/1918.

p.2

7. Correio Paulistano 26/09/1918. p. 4 condições anormais de vida que nos assoberbam, oriundos da conflagração europeia." ${ }^{5}$

Ao passo que a gripe se fazia cada vez mais presente no cenário da Primeira Guerra, em setembro de 1918 chegou a notícia do adoecimento de membros da Missão Médica Brasileira pela doença a bordo do navio $L a$ Plata a serviço na guerra, cuja infecção teria ocorrido em Dakar, na África. Em 23 de setembro, o Correio Paulistano publicava a coluna $\mathrm{A} \ll$ Influenza Hespanhola $>$, noticiando: "Os surtos epidêmicos nas unidades da divisão naval brasileira em operações de guerra - As medidas tomadas pelo sr. ministro da Marinha", que transcrevia as notas do Jornal do Commercio, do Rio de Janeiro, confirmando mais casos de gripe na esquadra naval. ${ }^{6}$ Três dias depois, em 26 de setembro, foi a vez do Governo Federal, por meio da Diretoria de Saúde Pública, anunciar medidas à Companhia de Navegação Lloyd Brasileiro para frear o avanço da epidemia no país pelos portos:

O Lloyd Brasileiro teve hoje communicação da Directoria de Saúde Pública que d'ora avante, todos os navios procedentes de portos extrangeiros europeus, africanos e asiáticos, como os sem escalas pelos nacionaes, ficam sujeitos, até segunda ordem, a visita sanitária em todos os portos do Brasil em que tocarem, mesmo trazendo a bordo inspector sanitário marítimo?.

Antes de a medida ser anunciada, a gripe já se encontrava no Rio de Janeiro. Avalia-se que desde agosto o vírus já estaria na capital, ainda que pela análise da maioria das fontes tivesse desembarcado oficialmente na cidade em 14 de setembro a bordo do navio inglês Demerara, depois de aportar em Salvador e Recife (GOULART, 2003, p. 31-32). Com o irrompimento da doença, em 30 de setembro o Diretor Geral de Saúde Pública, Carlos Pinto Seidl, estabeleceu um serviço de assistência domiciliar e de socorros públicos aos necessitados. Era o reconhecimento oficial do estado pandêmico que a gripe atingia na capital federal (Idem, 2003, p. 34).

Pouco tempo depois, em 9 de outubro de 1918, a gripe chegou a São Paulo, como consta no relatório de Meyer e Teixeira (1920, p. 4), quando se hospedaram no Hotel d'Oeste no Largo São Bento, no centro da cidade, 
jogadores amadores de futebol infectados pela doença provenientes do Rio de Janeiro. No dia 13 daquele mês, deu entrada no Hospital de Isolamento o primeiro doente de gripe, cuja notificação iniciou a mobilização do Serviço Sanitário em seu combate.

\section{O Serviço Sanitário do Estado e a epidemia de gripe espanhola}

Em 14 de outubro de 1918, um dia após dar entrada o primeiro doente de gripe, uma reunião foi convocada por Arthur Neiva com o Diretor da Assistência Pública, Raul de Sá Pinto, e os Delegados de Saúde do Estado. Nela, deliberou-se a assistência domiciliar aos doentes, a assistência médica pelas Delegacias de Saúde e a solicitação da Hospedaria de Imigrantes à Secretaria de Agricultura para a instalação de um hospital provisório (/dem, 1920, p. 4-5). Medidas que, apesar de aprovadas em 14 de outubro, já teriam sido aventadas pelo Serviço Sanitário dado o conhecimento do que se passava no Rio de Janeiro - como se realça no relatório.

Após a deliberação, a Secretaria do Interior do Estado iniciou a organização de ações conjuntas, mobilizando iniciativas públicas e privadas. Foram instalados 40 hospitais provisórios na capital, cuja coordenação ficou a cargo do doutor Arnaldo Vieira de Carvalho, Diretor da Faculdade de Medicina de São Paulo, e a superintendência econômica sob responsabilidade do doutor Alfredo Pujol da Comissão de Socorros Estado-Fanfulla. 0 expediente do serviço de enfermeiros para hospitais e residências domiciliares ficou a cargo da Cruz Vermelha, e as visitas domiciliares de socorros em alimentos, dinheiro e amparo, sob responsabilidade do Reverendo Dom Duarte Leopoldo, arcebispo de São Paulo. Também foram instalados 44 postos de socorro na cidade confiados ao doutor Frederico Vergueiro Steidel, presidente da Liga Nacionalista. Já a estatística de despachos feita pelos escoteiros foi delegada ao doutor José Carlos de Macedo Soares (Idem,1920, p. 13-14).

A organização também contou com o corpo discente da Faculdade de Medicina, disponibilizado por Arnaldo Vieira de Carvalho; com as associações religiosas no amparo aos necessitados e na instalação de hospitais; 
0 Combate $17 / 10 / 1918$ p. 1 com o Posto Médico da Assistência Policial; com os três Postos Portugueses de Socorro instalados pela colônia portuguesa; com a Associação Comercial de São Paulo na organização de donativos e manutenção da Polyclinica de São Paulo; com a União Farmacêutica, atuante no Rio de Janeiro, sob chefia de José Ribeiro Pereira, que ofereceu seus serviços ao Serviço Sanitário paulista; com a Sociedade Italiana Ospedale Umberto I na manutenção do Hospital Pro-Grippados; com a Instrução Pública ao disponibilizar seus médicos por determinação do Secretário do Interior; e com a Força Pública do Estado, responsável por organizar seis hospitais (Idem, 1920. p. 13-14).

À Prefeitura de São Paulo coube a mobilização dos serviços que executava: a comunicação, pela Companhia Telephonica; os transportes de luz e força, pela Companhia Light \& Power; e o serviço funerário, que acabou concedido à Santa Casa de Misericórdia por intermédio da Casa Rodovalho. Em 26 de outubro de 1918, a Resolução no 131 autorizou o Prefeito Washington Luis a tomar "todas as providências necessárias à assistência pública, relativamente a pandemia reinante" (SÃO PAULO (Município), 1918). Ao fim daquele mês, serrarias, carpintarias e tapeçarias foram mobilizadas para a confecção de caixões, até que em 7 de novembro, pelo Ato $n^{\circ} 1.274$, foram suspensas as tabelas de preços do serviço funerário enquanto durasse a epidemia, reduzindo os valores devido à demanda provocada pelas mortes (SÃO PAULO (Municipio), 1918).

A Diretoria Geral do Serviço Sanitário estabeleceu uma comunicação diária com a imprensa, reunida no relatório de Meyer e Teixeira (1920, p. 71-156) de 16 de outubro a 19 de dezembro de 1918, em que se comunicava os casos de gripe na capital e no interior remetidos pelas Delegacias de Saúde e pelos municipios. Ainda informava sobre as medidas tomadas pelo Serviço Sanitário para evitar a propagação da doença e dava instruções sobre a assistência sanitária, medicamentos, além de emitir boletins de medidas profiláticas ao longo da epidemia.

Ao início das comunicações, em 17 de outubro, o Serviço Sanitário reagia à "indecorosa especulação dos droguistas e farmacêuticos", como qualificou o jornal 0 Combate $^{8}$, alertando-os sobre possíveis punições decorrentes do aumento do preço das substâncias indicadas 
Nota-se pelo relatório que o Dr. Lyra Porto atuou em Santos e Cunha; o Dr. Pericles Reis em Avaré, Itapecerica e Itaporanga; o Dr. Crissiuma Paranhos em

Serra Negra e Itararé; o Dr. Caiado de Castro em Batataes e Espírito Santo do Pinhal; o Dr. Amphilophio de Mello em São Luiz do Paraitinga e Campinas; entre outros. para a prevenção à gripe (apud MEYER; TEIXEIRA, 1920, p.72). Já no comunicado do dia 24 do mesmo mês, o próprio Serviço anunciava que passaria a vender tais medicamentos a preço de custo em seu Almoxarifado, além de conceder receitas gratuitas pelas Delegacias de Saúde para retirada nas farmácias. Suas substâncias eram: alcoolato de canela, água purgativa de "L. Queiroz", cloridrato e sulfato de quinino, limonada purgativa de citrato de magnésia, mentol e cânfora, sulfato de magnesia, sulfato de sódio, tintura de iodo, e vaselina com 3\% de mentol (apud MEYER; TEIXEIRA, 1920, p. 87).

Em 25 de outubro, o comunicado do Diretor do Serviço Sanitário, Arthur Neiva, frisou a "impossibilidade absoluta, derivada da falta de pessoal e da crise de meios, de atender o Serviço Sanitário à tarefa de combater o mal nos diferentes municípios do Estado", cabendo às municipalidades "organizar, com pessoal e recursos próprios, a campanha contra a epidemia, dentro dos respectivos municípios, não convindo de modo algum que se limitem a requisitar e esperar ação exclusiva do Serviço Sanitário" (apud MEYER; TEIXEIRA, 1920, p. 89). Era o prenúncio de uma situação inédita, sobretudo para os municípios do interior.

0 artigo 8 do Código Sanitário ditava que "em épocas anormais as municipalidades entregarão ao Governo, logo que este o requisite, o serviço sanitário que estiver a cargo do município" (São Paulo (Estado), 1918), algo condizente com o que havia sido até então praticado, mas que não ocorreu durante a epidemia mesmo que fosse esperado ou de agrado às municipalidades. Coube então aos municipios do interior assumir uma responsabilidade diferente da que estavam habituados, e que desde a gestão de Emílio Ribas se fortaleceu a cargo do Serviço Sanitário: a luta contra uma doença epidêmica.

\section{A municipalização das ações na epidemia}

No relatório, há a listagem de 41 municípios socorridos pela Diretoria do Serviço Sanitário com o nome do respectivo médico responsável e o número de estudantes e auxiliares (quando era o caso), que por vezes atuaram em mais de um municipio, realizando visitas a hospitais e a enfermos (MEYER; TEIXEIRA, 1920, p. 164-165). ${ }^{9}$ 
10.

Idem. p. 255, 295 e 299. Os

municipios de Lorena e Paraibuna

relatam a solicitação ao Secretário

do Interior durante a epidemia; já

o de Casa Branca, ao Presidente

do Estado.

11.

Nota-se que o relatório menciona a disponibilização de médicos pela Instrução Pública por determinação do Secretário do Interior, como abordado anteriormente. Pode-se considerar o envio de médicos pela Secretaria do Interior não vinculados ao Serviço Sanitário.
Entretanto, na seção do relatório com as informações e relatos enviados pelos municipios do interior, alguns informam que solicitaram auxilio de pessoal diretamente ao Secretário do Interior, Oscar Rodrigues Alves - como é o caso de Lorena e Paraibuna -, e que tiveram suas solicitações atendidas apesar de não constarem na lista dos 41 municípios socorridos pelo Serviço Sanitário (Idem, 1920, p. 255,295$).^{10} 11$

É possível que a incongruência dos relatos com a listagem tenha ocorrido por omissão do relatório, pela falta de padronização neste tipo de requerimento ou por negativa anterior do Serviço Sanitário em atender à solicitação, recorrendo-se à autoridade superior. No caso do município de Casa Branca, diferente de Lorena e Paraibuna, o relato enviado informa que foi solicitado auxilio ao Presidente do Estado, Altino Arantes, constando na lista de municipalidades socorridas pelo Serviço Sanitário. Dentre as socorridas, a primeira foi em Lagoinha pelo Dr. Bastos Cruz; a segunda pelo Dr. José Toledo Piza que não consta ter atuado em nenhuma das localidades listadas pelo Serviço Sanitário.

No municipio de Santos, sede da respectiva Delegacia onde o primeiro óbito por gripe tinha sido registrado no dia 9 de outubro, data em que a doença chegava a São Paulo, três médicos foram enviados pelo Serviço Sanitário e foram registradas 847 mortes por gripe (Idem, 1920, p. 164-167). Em Campinas, onde o Serviço montou o Hospital do Sagrado Coração - que não chegou a funcionar devido à demanda de mais recursos pela lotação do Hospital da Cruz Vermelha -, três médicos com cinco estudantes foram enviados e 209 óbitos por gripe foram registrados (Idem. 1920, p. 164, 179-181). Ribeirão Preto, ao verificar a presença da moléstia, solicitou a autorização do Serviço Sanitário para a montagem de um hospital, instalado no Theatro Casino Antarctica, sendo que dois médicos e dois estudantes foram enviados e 205 mortes por gripe foram registradas (Idem. 1920, p. 164, 222223). As sedes das demais Delegacias de Saúde, como São Carlos, Guaratinguetá e Botucatu, não contaram com o envio de pessoal e registraram o menor número de óbitos por gripe em comparação às citadas: 139, 90 e 55 óbitos, respectivamente (Idem, 1920, p. 164). 


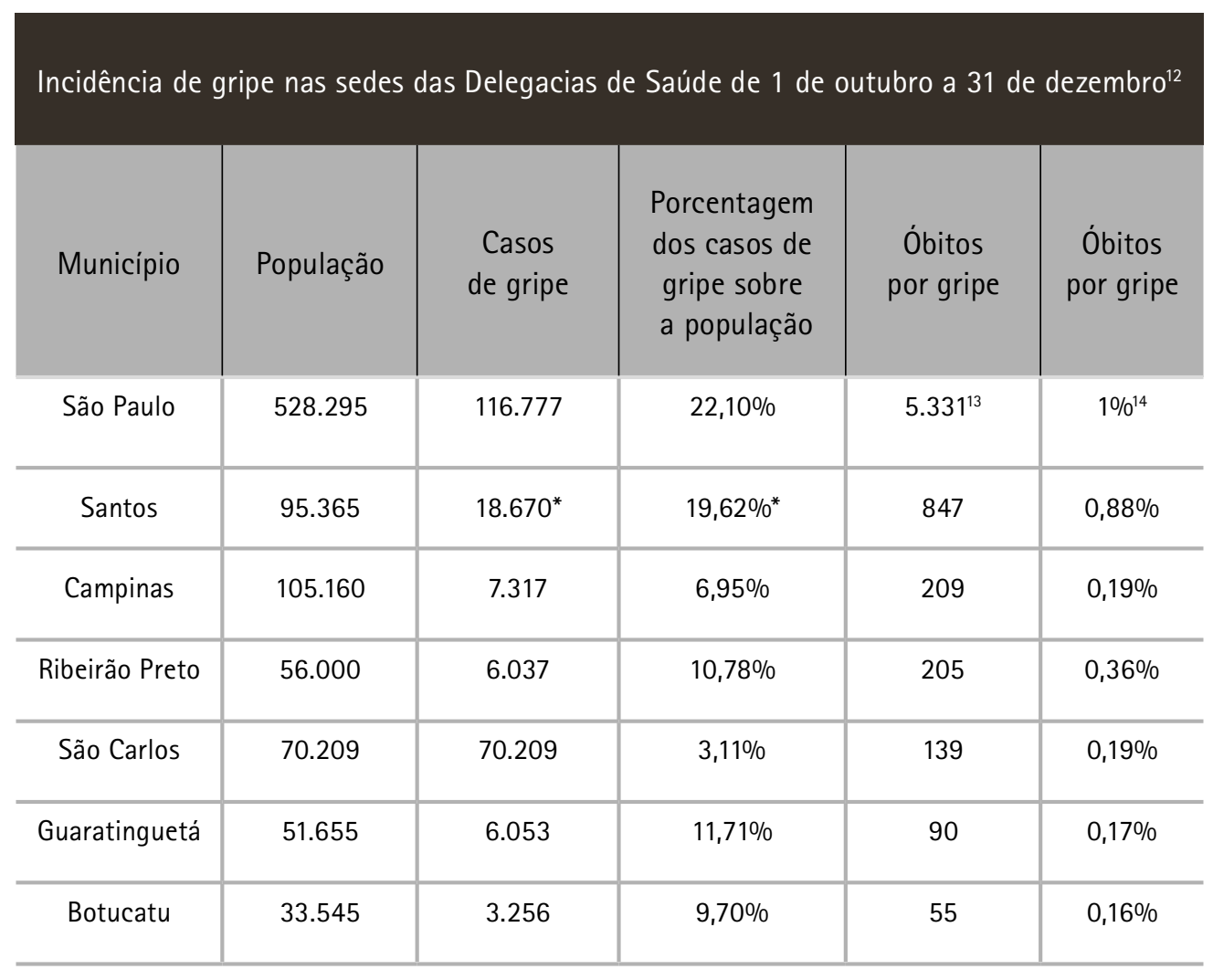

* Número estimado. 0 relatório acusa que mais de 10.000 pessoas foram atendidas em Santos durante a epidemia e confirma 847 óbitos por gripe. Obtendo a porcentagem de 0,88\% de mortes por gripe sobre a população em Santos e 1\% em São Paulo, estimou-se a incidência de gripe sobre 19,62\% população, equivalente a 18.670 doentes, em comparação com os números da capital.

12.

Gráfico elaborado a partir das informações do relatório de Meyer e Teixeira.

13.

A estatistica reconhece 5.331

óbitos por gripe, mas Meyer

e Teixeira consideram que a

cifra correta seria de 6.861.

Mantivemos os dados com as

informações tabuladas no rela-

tório.

14.

Idem. Corrigindo-se os dados em 6.861 óbitos, obtém-se $1,29 \%$. 


\begin{tabular}{c|c|c|c|c|c} 
Mortalidade por gripe no Estado de São Paulo de 1 de outubro a 31 de dezembro de $19181^{15}$ \\
Município & População & $\begin{array}{c}\text { Óbitos } \\
\text { por gripe }\end{array}$ & $\begin{array}{c}\text { Óbitos } \\
\text { em geral }\end{array}$ & $\begin{array}{c}\text { Porcentagem } \\
\text { da gripe } \\
\text { sobre o total } \\
\text { de mortos }\end{array}$ & $\begin{array}{c}\text { Coeficiente } \\
\text { dos óbitos de } \\
\text { gripe por mil } \\
\text { habitantes }\end{array}$ \\
\hline São Paulo & $528.295^{16}$ & 5.331 & 8.848 & $60,25 \%{ }^{17}$ & 40,36 \\
\hline Santos & 95.365 & 847 & 1.377 & $61,51 \%$ & 35,52 \\
\hline Campinas & 105.160 & 209 & 677 & $30,87 \%$ & 7,94 \\
\hline Ribeirão Preto & 56.000 & 205 & 513 & $39,96 \%$ & 14,51 \\
\hline São Carlos & 70.209 & 139 & 341 & $40,76 \%$ & 7,91 \\
\hline Guaratinguetá & 51.655 & 90 & 477 & $18,86 \%$ & 6,96 \\
\hline Botucatu & 33.545 & 55 & 221 & $24,88 \%$ & 6,55 \\
\hline Outros do & 3.300 .000 & 5.510 & 24.200 & $22,76 \%$ & 6,67 \\
\hline Total & $\mathbf{4 . 4 2 0 . 2 2 9}$ & $\mathbf{1 2 . 3 8 6}$ & $\mathbf{3 6 . 6 5 4}$ & $\mathbf{3 3 , 7 9 \%}$ & $\mathbf{1 5 , 0 1}$ \\
\hline
\end{tabular}

15.

Gráfico transcrito do relatório de Meyer e Teixeira. Op. Cit., p. 404.

16.

Ver nota 12.

17.

Ao tomar como referência 6.861 óbitos, eleva-se a porcentagem para $77,54 \%$.
As medidas tomadas no combate à gripe espanhola se basearam na experiência com epidemias anteriores, principalmente malária, febre amarela, peste bubônica e febre tifoide, consistindo em quatro principais pilares: isolar os doentes, desinfetar as residências onde ocorressem óbitos pela moléstia, intensificar a vigilância epidemiológica e publicar conselhos à população (BERTOLLI, 2003, p. 156). Entretanto, pela maneira que a doença irrompeu, tais medidas apresentaram dificuldades de implementação.

Ainda em outubro, diferente do discurso oficial que insistia que na cidade de São Paulo não existiam 
as mesmas consequências funestas do Rio de Janeiro e que a população deveria seguir as recomendações do Serviço Sanitário, a incidência de gripe parecia maior aos paulistanos do que os números divulgados pelo mesmo órgão (BERTUCCI-MARTINS, 2002, p. 112). Cedendo às pressões populares por uma terapêutica preventiva efetiva, o Serviço Sanitário publicou na imprensa em 26 de outubro as "fórmulas mais usadas no combate a gripe" que, no entanto, não continham qualquer nova droga além daquelas já prescritas por médicos e divulgadas pela imprensa, como calomelanos, compostos de quininos e aspirinas, mostrando-se ineficazes no tratamento dos gripados (BERTOLLI, 2003, p.160).

No âmbito da pesquisa, o Instituto Butantan buscou desenvolver uma vacina polivalente, tarefa incumbida aos Drs. João Florêncio Gomes e Arlindo Raymundo de Assis, que foi aplicada em médicos e funcionários do Instituto e em 91 oficiais do $1^{\circ}$ Batalhão da Força Pública. Também buscou-se elaborar um soro anti-pneumocócico, contando com um cavalo imunizado e ensaios terapêuticos com soro normal de cavalo, sob responsabilidade dos Drs. Oscar Freire de Carvalho e Afrânio do Amaral na Santa Casa de Misericórdia (MEYER; TEIXEIRA, 1920. p. 157). Essas iniciativas foram restritas e não tiveram sua eficácia comprovada.

\section{As insuficiências do Serviço Sanitário frente à epi- demia: repercussões na imprensa}

Ainda que Neiva reiterasse a plena capacidade do Serviço Sanitário para enfrentar a epidemia, o medo generalizado tomava conta da população e não faltavam críticas à sua gestão (BERTOLLI, 2003. p.162). Apesar do apoio às medidas governamentais, a imprensa pontuou discordâncias com as ações executadas até então. Um dos articulistas do jornal 0 Estado de S. Paulo declarava, em 21 de outubro, que não poderia mais manter a atitude que até aquela data havia sustentado quanto ao combate à gripe, pois as "medidas deparam falhas lamentáveis" (apud BERTUCCI-MARTINS, 2002, p. 117). Outro artigo do mesmo jornal questionava, em 27 de outubro, o sistema de socorros montado pelo Serviço Sanitário: "Todavia, 
18.

0 Combate 09/11/1918 p.1

19.

Observa-se nos relatos que 0

Serviço Sanitário enviou "pessoal

médico, turma de desinfecta-

dores e enfermeiros" a Jundiai, um

médico para Caçapava e Taubaté

um doutorando a Montemor e

inspetores sanitários a Socorro,

Caconde, São José do Rio Pardo,

Bananal e Porto Feliz. ainda uma vez diremos, há alguma desorganização nisso tudo." (Idem, 2002, p. 135).

A dificuldade de se hospitalizar todos os enfermos e, consequentemente, isolar os doentes, fez da organização da assistência médica e terapêutica uma alternativa viável para tratar os infectados, o que foi duramente criticado. 0 jornal 0 Combate, no dia 1 de novembro, era categórico ao afirmar: "0 remédio, repetimos, está na hospitalização" (Idem, 2002, p. 141). Nessa ocasião, a mortalidade diária por gripe já atingia as centenas. 0 mesmo jornal, no dia 8 daquele mês, subiu o tom das críticas ao publicar A "hespanhola" - A verdade é que não temos Serviço Sanitário, denunciando a falta de remédios, de alimentos e que o obituário por gripe tendia a crescer pela "falta da mais rudimentar profilaxia" (apud BERTOLLI, 2003, p. 170).

0 salto de casos de gripe na capital ao fim de outubro e começo do mês seguinte cerceou o Serviço Sanitário de tal maneira que, já ao início de novembro, seu papel se restringiu a coordenar a atuação das associações empenhadas no socorro da capital que, em outra crítica do jornal 0 Combate, carregavam "a maior parte do peso que o oprimia"18, além de divulgar dados sobre a gripe e informações sobre o funcionamento de hospitais e postos de socorros (BERTOLLI, 2003, p.170-171). Arthur Neiva e o prefeito Washington Luís passaram a visitar cotidianamente os hospitais da capital paulista, até adoecerem de gripe por volta de 10 de novembro. Joaquim Rabello Teixeira, coautor do relatório, assumiu a Direção do Serviço Sanitário, cuja atuação parecia desacreditada, tornando mais lacônicos os comunicados à população sobre a epidemia (Idem, 2003).

Em meados de novembro, quando a marcha da doença entrava em declínio na capital paulista, o Serviço Sanitário se voltou para o interior, mas longe de qualquer protagonismo. Ambulâncias, medicamentos e, em alguns casos, médicos, enfermeiros, desinfetadores e inspetores sanitários foram enviados ao interior, como relatam alguns municipios ${ }^{19}$. No entanto, as ações coordenadas de combate à gripe ficaram a cargo das respectivas localidades, municípios e Delegacias de Saúde, que foram socorridas tardiamente com a mobilização de pessoal e de funcionários basicamente restritos à cidade de São Paulo durante a epidemia (Idem, 2003, p. 171). 
20.

Pela tabela de Mortalidade no

Estado apresentada pelo relatório, alguns municipios apresentaram mais óbitos em dezembro que em novembro.
Da primeira notificação em 13 de outubro ao fim de dezembro de 1918 foram registrados, na cidade de São Paulo, 29.900 casos de gripe no mês de outubro, 86.366 em novembro e 511 em dezembro, totalizando 116.777 casos - pouco mais de um quinto da população paulistana. Quanto ao número de mortes, os registros oficiais apontavam um total de 5.331 óbitos por gripe que, segundo Meyer e Teixeira, era incongruente com os números do Registro Civil, que apresentavam um aumento de 1.972 óbitos em relação ao mesmo trimestre do ano anterior, totalizando 6.861 mortes por gripe considerando a subnotificação (MEYER; TEIXEIRA, 1920, p. 48-58).

0 impacto que a gripe teve na cidade até meados de novembro foi tão devastador que, no dia 18 daquele mês, a Prefeitura de São Paulo desapropriou um terreno próximo ao cemitério do Araçá para sua expansão devido à calamidade provocada pela doença (SÃO PAULO (Município), 1918c). Ao fim de novembro, além da capital, a doença já dava sinais de declínio nas outras sedes de Delegacias de Saúde, registrando em dezembro um número de óbitos inferior ao do mês antecedente. Em alguns municipios do interior ainda se registrava um número de óbitos superior (MEYER; TEIXEIRA, 1920, p.396-403). ${ }^{20}$

\section{Considerações finais}

Entre outubro e dezembro de 1918, toda estrutura do Serviço Sanitário foi posta à prova contra um mal nunca antes enfrentado pela maneira que irrompeu. Em outras ocasiões, ainda que se tivesse combatido epidemias em localidades específicas ou mantendo-as sob controle, nenhuma conseguiu atingir as mesmas proporções em todo o Estado tornando sua presença simultânea em diversas localidades como a gripe espanhola o fez em 1918.

Nesta situação inédita, a falta de conhecimento especifico da doença dificultou a tomada de decisão em seu combate (BERTOLLI, 2003, p.171-172). 0 Estado e o Serviço Sanitário se empenharam dentro de suas possibilidades para debelar a gripe, o que não se mostrou suficiente frente à crescente desconfiança da população e à desesperança das próprias autoridades paulistas com o Serviço Sanitário do Estado. 
Em comparação à capital federal, Rio de Janeiro onde, segundo o relatório, mais de 600.000 dos 915.000 habitantes adoeceram, equivalente a $65 \%$ da população carioca (MEYER; TEIXEIRA, 1920, p. 496-498) -, em São Paulo o número de doentes foi de 116.777, equivalente a $22,10 \%$ da população paulistana. Em relação ao número de óbitos no Rio de Janeiro foram registrados 11.953, 1,3\% da população, já em São Paulo se registraram 5331 mortes representando $1 \%$ da população. (idem $1920 \mathrm{p}$ 59-60)

Estes dados podem ter embasado o entusiasmo de Neiva, Teixeira e Rabello com as ações do Serviço Sanitário de São Paulo durante a feitura do relatório publicado em 1920, que realça a comparação entre as duas cidades ao abordar os casos e óbitos de gripe na capital paulista (Idem.1920, p.60). Porém, ainda que sob o contentamento da comparação, tal entusiasmo não se verificou com as impressões vividas durante a epidemia, com as críticas da imprensa, o medo generalizado da população e a atuação tardia nas localidades do interior. Nesta perspectiva, a atuação do Serviço Sanitário se distanciou tanto do otimismo de sua classe médica como do pessimismo de atores sociais durante a epidemia e das constantes cobranças ao Serviço Sanitário. 0 relatório apresenta uma narrativa ajustada para enaltecer a atuação do Serviço Sanitário do Estado de São Paulo, que $o$ escusa das deficiências apontadas pela imprensa no período, contrastando-se com o documento.

0 impacto provocado pela gripe espanhola em 1918 se coloca como um ponto de inflexão para o Serviço Sanitário do Estado. Se em Campinas, a segunda cidade mais populosa do Estado, a vivência traumática com a febre amarela ao fim do século XIX parecia ter deixado a cidade alerta, reunindo ações públicas e particulares no combate à gripe (BERTUCCI-MARTINS, 2005, p. 5) e resultando num baixo número de óbitos sobre a população (0,19 comprado a Santos e São Paulo), a dura experiência com a epidemia gripal em todo o Estado pode ter contribuído para a reorientação das políticas sanitárias.

Um ano após a epidemia, em 1919, o artigo 562 do Código Sanitário que tratava das doenças de notificação compulsória foi alterado com a inclusão da Influenza (DUARTE, 2009). Em 1925 foi reorganizado o 
Serviço Sanitário, fruto da da gestão de Geraldo Horácio de Paula Souza, havendo mudanças como o aperfeiçoamento das práticas de isolamento de doentes, expurgo e desinfecção de locais de infecção; montagem de hospitais de isolamento de emergência com a criação da Inspetoria de Moléstias Infecciosas; e a ênfase na saúde rural com a Inspetoria de Higiene dos Municipios, que ainda foi responsável pela instalação de um posto permanente de saúde em cada um dos 217 municipios do Estado (FARIA, 2002). 


\section{Referências bibliográficas}

A "HESPANHOLA" EM SÃO PAULO: A indecorosa especulação dos droguistas e pharmaceuticos. 0 Combate, São Paulo, ano IV, n. 1.029, p. 1, 17 out. 1918. Disponivel em: http://memoria.bn.br/DocReader/ DocReader.aspx?bib=830453\&Pesq $=$ hospitaliza\% $\%$ c3\%a7\%c3\%a3o\&pagfis=1500. Acesso em 3 jun. 2019.

A "HESPANHOLA": Afinal faz-se um pouco de ordem. 0 Combate, São Paulo, ano IV, n. 1.046, p. 1, 9 nov. 1918. Disponivel em: http://memoria.bn.br/ DocReader/docreader.aspx?bib $=830453 \&$ pasta $=$ ano $\% 20191$ \& pesq $=$ hospitaliza \%C3\%A7\%C3\%A3o\&pagfis=1540. Acesso em 3 jun. 2019.

A INFLUENZA HESPANHOLA: Os surtos epidemicos nas unidades da divisão naval brasileira em operações de guerra - As medidas tomadas pelo sr. ministro da Marinha. Correio Paulistano, São Paulo, ano 248, n. 19.834, p. 2, 23 set. 1918. Disponivel em: http://memoria.bn.br/DocReader/090972_06/47857. Acesso em 31 mai. 2019.

A INFLUENZA HESPANHOLA: 0 Governo Federal toma medidas rigorosas no sentido de evitar a invasão da epidemia no Brasil. Correio Paulistano, São Paulo, ano 248, n. 19.837, p. 4, 26 set 1918. Disponivel em: http://memoria.bn.br/docreader/090972_06/47887. Acesso em 31 mai. 2019.

BRASIL. IBGE, Censo Demográfico, 1890. Disponivel em: https://memoria.ibge.gov.br/sinteses-historicas/ historicos-dos-censos/censos-demograficos.html. Acesso em: 17 nov. 2020.

BERTOLLI, C. A Gripe Espanhola em São Paulo, 1918: Epidemia e Sociedade. São Paulo: Editora Paz e Terra, 2003

BERTUCCI-MARTINS, L. Aprendendo com o passado. Campinas e a gripe de 1918. In: SIMPÓSIO NACIONAL DE HISTÓRIA, 23., 2005, Londrina, PR. Anais... Londrina: ANPUH, 2005. p. 5. Disponivel em: http:// www.snh2011.anpuh.org/resources/anais/anpuhnacional/S.23/ANPUH.S23.1335.pdf Acesso em 23 ago. 2019 
BERTUCCI-MARTINS, L. Influenza, a medicina enferma: Ciência e práticas de cura na época da gripe espanhola em São Paulo. 2002. Tese (Doutorado em História) - Instituto de Filosofia e Ciências Humanas, Universidade Estadual de Campinas, Campinas.

BLOUNT, III, John Allen. A administração da saúde pública no estado de São Paulo o serviço sanitário 18921918. Rev. adm. empres., São Paulo , v. 12, n. 4, p. 40-48, Dec. 1972. Disponivel em: http:// www.scielo.br/scielo.php?script=sci_arttext\&pi$d=$ S0034-75901972000400003\&lng $=$ en \&nrm $=$ iso. acesso em 23 ago. 2019.

DUARTE, Ivomar Gomes. 0 código sanitário estadual de 1918 e a epidemia de gripe espanhola. Cad. hist. ciênc., São Paulo, v. 5, n. 1, jun. 2009 . Disponivel em http://periodicos. ses.sp.bvs.br/scielo.php?script=sci_arttext\&pi$\mathrm{d}=\mathrm{S} 1809-76342009000100004 \& \operatorname{lng}=\mathrm{pt} \& \mathrm{nrm}=$ iso. acesso em 26 ago. 2019.

FARIA, Lina Rodrigues de. A Fundação Rockefeller e os serviços de saúde em São Paulo (1920-30): perspectivas históricas. Hist. cienc. saude-Manguinhos, Rio de Janeiro, v. 9, n. 3, p. 561590, Dec. 2002 . Disponivel em: http:// www.scielo.br/scielo.php?script=sci_arttext\&pi$\mathrm{d}=\mathrm{S} 0104=59702002000300005-\& \mathrm{lng}=\mathrm{en} \& \mathrm{nrm}-$ iso. acesso em 28 ago. 2019. http://dx.doi. org/10.1590/S0104-59702002000300005.

FOUCAULT, Michel. A microfísica do poder. Rio de Janeiro: Edições Graal, 1984.

GOULART, A. da C. Um cenário mefistofélico: a gripe espanhola no Rio de Janeiro. 2003. Dissertação (Mestrado em História) - Programa de Pósgraduação em História, Universidade Federal Fluminense, Niterói.

HOCHMAN, G. A era do saneamento: as bases da politica de saúde pública no Brasil. São Paulo: Hucitec, 2006.

MASCARENHAS, Rodolfo dos Santos. História da saúde pública no Estado de São Paulo. Rev. Saúde Pública, São Paulo, v. 40, n. 1, p. 3-13, Feb. 2006 . Disponivel em: http:// www.scielo.br/scielo.php?script=sci_arttext\&pi- 
$d=S 0034-89102006000100002 \& \operatorname{lng}=$ en\&nrm $=$ iso. acesso em 28 Aug. 2019. http://dx.doi.org/10.1590/ S0034-89102006000100002.

MEYER, C. L.; TEIXEIRA, J. R. A grippe epidemica no Brazil e especialmente em São Paulo.Prefácio de Arthur Neiva. São Paulo: Casa Duprat, 1920.

NOTAS. Correio Paulistano, São Paulo, ano 248, n. 19.685, p. 1, 27 abr. 1918. Disponivel em: http:// memoria.bn.br/docreader/DocReader.aspx?bi$b=090972 \_06 \&$ pagfis $=47859$. Acesso em 31 mai. 2019

O CODIGO SANITARIO: Uma circular do Sr. Secretario do Interior. Correio Paulistano, São Paulo, ano 248, n. 19.705, p.2, 17 mai. 1918. Disponivel em: http://memoria.bn.br/docreader/DocReader.aspx?bi$b=090972 \_06 \&$ pagfis $=46545$. Acesso em 31 mai. 2019

SÃO PAULO (Estado). Decreto n. 2.918, de 9 de abril de 1918. Dá execução ao Código Sanitário do Estado de São Paulo. Assembleia Legislativa do Estado de São Paulo. São Paulo, SP. Disponivel em: https:// www.al.sp.gov.br/norma/?id=134547 Acesso em: 11 nov. 2020

SÃO PAULO (Estado). Lei n. 43, de 18 de julho de 1892. Organiza o serviço sanitário do Estado. Assembleia Legislativa do Estado de São Paulo. São Paulo, SP. Disponivel em:https://www.al.sp.gov. br/norma/64128. Acesso em: 11 nov. 2020.

SÃO PAULO (Estado). Lei n. 1.596, de 29 de dezembro de 1917. Reorganiza o Serviço Sanitário do Estado. Assembleia Legislativa do Estado de São Paulo. São Paulo, SP. Disponivel em: https://www.al.sp.gov. br/norma/65811. Acesso em 11 nov. 2020.

SÃO PAULO (Estado). Lei n. 432, de 3 de agosto de 1896. Sobre o Serviço Sanitário. Assembleia Legislativa do Estado de São Paulo. São Paulo, SP. Disponivel em:https://www.al.sp.gov.br/norma/64523. Acesso em: 11 nov. 2020

SÃO PAULO (Município). Ato n. 1.274, de 7 de novembro de 1918. Suspende, enquanto durar a epidemia, as tabelas de preços e classes para a execução do serviço funerário, e dá outras providências. Câmara Municipal de São Paulo. São Paulo, SP. 
Disponivel em: http://legislacao.prefeitura.sp.gov. br/leis/ato-gabinete-do-prefeito-1274-de-7-de-novembro-de-1918 Acesso em: 22 nov. 2020.

SÃO PAULO (Município). Ato n 1.278 , de 18 de novembro de 1918. Declara de utilidade pública, para desapropriação judicial, uma área de terreno necessária ao aumento do cemitério do Araçá. Câmara Municipal de São Paulo. São Paulo, SP. Disponivel em: http:// legislacao.prefeitura.sp.gov.br/leis/ato-gabinete-do-prefeito-1278-de-18-de-novembro-de-1918 Acesso em: 11 nov. 2020 